\title{
Expression of Cyclooxygenase-2 (COX-2) in Colorectal Adenocarcinoma: an Immunohistochemical and Histopathological Study
}

\author{
Abla Sayed Mahmoud ${ }^{1}$, Ayesha Umair ${ }^{2}$,Saleh Nasser Azzeghaiby², Fahad Hussain \\ Alqahtani $^{2}$, Salah Hanouneh ${ }^{3}$, Bassel Tarakji ${ }^{3 *}$
}

\begin{abstract}
Background: The aim of this study was to evaluate cyclooxygenase-2 (COX-2) immunoreactivity in colorectal adenocarcinomas and to find correlations with different pathological features. Materials and Methods: This study included 35 cases of colorectal carcinoma foir which surgical colectomy specimens were collected. Immunohistochemical staining of COX-2 (cyclooxygenase-2) is done by using the Streptavidin-biotin technique. Results: This work reveals that COX-2 is positive in most cases of colorectal carcinoma and negative in normal colon tissue with statistically non significant relations between COX-2 immunostaining and different pathological features.-Conclusions: Our data suggest over expression of COX-2 protein in colorectal carcinoma in contrast to normal mucosa, with a possible role in cell proliferation in carcinogenesis.
\end{abstract}

Keywords: COX-2 - antibodies - colorectal adenocarcinoma - immunohistochemistry

Asian Pac J Cancer Prev, 15 (16), 6787-6790

\section{Introduction}

Colorectal cancer (CRC) is a major cause of mortality and morbidity worldwide, being the third most common malignant tumors in the world (Jemal et al., 2011), (Sameer et al., 2010). It results from both genetic and environmental factors and their interactions (Fatemi et al., 2010). In the last few years there have been many studies on the mechanisms involving the carcinogenesis of colorectal cancer. Inflammatory process and genetics play the key role in neoplasia of colorectal cancer. The identification of an enzyme COX-1 and COX-2, catalyzing fatty oxidation as rate limiting step in the progress from normal cell growth through hyperplasia or to neoplasia has opened up a whole new field of cancer search (Dempke et al., 2001). COX -1 and COX-2 catalyze the first stage in the oxidation of arachidonic acid to

prostaglandin (Karahan et al., 2007). Prostaglandin $\mathrm{E}(2)$ increases colon carcinogenesis through induction of cell proliferation and reduction of apoptosis (Kawamori et al., 2003). The majority of the colorectal cancers are derived from adenomas (Wu et al., 2003). It has been hypothesized that the up regulation of COX-2 prolongs the survival of abnormal cells and thereby favors the accumulation of sequential genetic changes, which increases the risk of tumorigenesis (Dempke et al., 2001). However, the over-expression of COX-2 protein in colorectal cancers is likely to occur via several different mechanisms involving complex signaling pathways, since transformed epithelial cells and stromal cells, such as mononuclear cells, fibroblasts, endothelial cells and smooth muscle cells have been shown to express increased levels of COX-2 (Sonoshita et al., 2002). COX2 is closely involved in the carcinogenesis process and is over expressed in adenocarcinoma in contrast with non-cancerous mucosal regions in colon cancers and gastric cancers (Tsujii et al., 1998). It is involved in a variety of important cellular functions, including cell growth and differentiation, cancer cell motility and invasion, angiogenesis and immune functions (Dempke et al., 2001). The role of angiogenesis is very important in colorectal cancer and cancercyclooxygenase- 2 is a significant angiogenic factor in colorectal cancer tissue (Zhou et al., 2012). Cox-2 is expressed highly in 80-90\% of colorectal adenocarcinoma mostly within the neoplastic epithelial cells (Zhang et al., 2002), (Tomozawa et al., 2000). Selective inhibition of Cox-2 reduces colorectal cancer in different models of carcinogenesis (Tuynman et al., 2005).

\section{Materials and Methods}

The study involved thirty five cases of colectomy specimens for human colorectal carcinoma that were 
obtained from pathology department, faculty of medicine, Cairo University during the period from March 2006 up to May 2007. Gross examination of each specimen was done to confirm its site, maximun gross diameter, infiltrating depth in the colon, its shape whether fungating, ulcerating or annular.

Sections were taken from the tumor avoiding the areas of hemorrhages and necrosis. The state of lymph node metastasis was obtained from the pathology report of each case.

Sections were fixed in $10 \%$ buffered formalin, dehydrated, cleared and embedded in paraffin wax according to routine processing procedures. Two sections ( $4 \mu$ thick) were then prepared from it to be stained with Hematoxylin and Eosin for histopathologic examination and Immunohistochemical staining by COX-2, using monoclonal rabbit anti-human antibody (anti-Cox2, Lab vision, USA, Cat\#RB-9072), using ultra vision detection system (HRP/DABh, Lab vision, USA).

The local NHS Research Ethics Committee provided a favorable ethical opinion (Ref: 02/104).

\section{Immunohistochemistry}

Paraffin-embedded, $4 \mu$ thick tissue sections from all 35 specimens were cut. The sections were deparaffinized in xylene and rehydrated through graded alcohols. Sections were processed using streptavidin- biotin-per-oxidase method. Briefly blocking endogenous peroxidase by $1.5 \%$ hydrogen peroxide in methanol for 15 minutes followed by Tris buffer solution (TBS) wash. Non-specific immunoreactivity was blocked by incubationl goat serum for 20 minutes. 2-3 drops of cox 2 antibody (diluted 1/200) was placed on each slide.

The slides were incubated for 45 minutes at room temperature in humid chamber. After tapping off excess reagent the slides were rinsed for 5 minutes. 2-3 drops of secondary antibody (biotinylated polyvalent) diluted in TBS were placed on each slide. The slides were incubated in a humidity chamber at room temperature for 15 minutes. Then slides were rinsed for 5 minutes in PBS, this procedure was repeated twice. Slides were incubated with Streptavidin enzyme label were placed on each slide and incubated for 15 minutes at room temperature in the humidity chamber; the slides were rinsed twice for 5 minutes in PBS. Incubated with a prepared chromogenic substrate solution for 15 minutes. Sections were counterstained with Mayer'hematoxyline for 1 minute then washed with water for 5 minutes. Sections were dehydrated and mounted in Depax.

All sections were examined for the grade of CRC: I, II, or III (including III, IV for simplicity) according to (Smyrk 2002). Figure 1 and Figure 2 depicts grade 1 and grade 3 of colorectal carcinoma respectively. The staging of carcinomas was done according to Dukes' classifications and presence or absence of vascular and perineural invasion by the tumor.

Positive immunoreactivity to COX-2 gives a brown cytoplasmic staining to tumor cells and not to the normal mucosal cells (Figure 3,4). The entire tissue section was scanned to assign the scores. The staining intensity was scored as 0 (negative), 1 (weak), 2 (medium), and 3 (strong). Extent of staining was scored as $0(0 \%), 1$ (1to $25 \%), 2$ (26 to $50 \%), 3$ (51 to $75 \%$ ) and 4 (76 to 100\%) according to the percentages of the positive staining areas in relation to the whole carcinoma area. The sum of the intensity and extent score was used as the final staining score (0 to 7$)$, tumors having a final staining score of $>$ or equal 3 were considered to be positive (Soumaoro et al., 2004).

Results were analyzed statistically using Fisher exact and chi square tests at a fixed significance level of 0.05 .

\section{Results}

COX-2 immunostaining in the studied cases were positive in most of cases (77\% of them) and negative in only $23 \%$ of cases. Regarding the histological grading, Grade II is the commonest grade in the studied colorectal adenocarcinoma cases $(51.4 \%)$ Table (4). The relation between COX-2 positivity and histological grade is statistically insignificant. The commonest location of the tumor in studied cases is the rectum and left side representing $43 \%$ of cases (Table 1). There is insignificant relationship between COX-2 immunostaining and site, size and gross appearance of the tumor (where most of cases in all sites are positive for COX-2). The results of correlation of COX 2 immunoreactivity to site, gross appreance, size, histological grade, lymph node involvement, Duke's

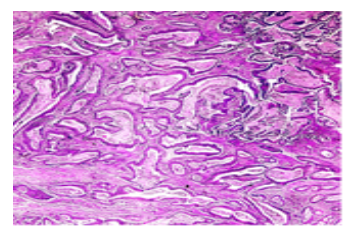

Figure 1. Colorectal Carcinoma Grade 1 (H\&E x 40)

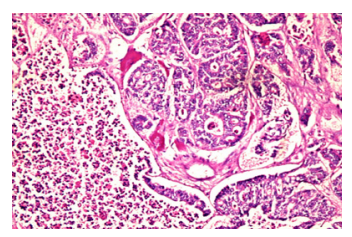

Figure 2. Colorectal Adenocarcinoma Grade III (H\& Ex 200)

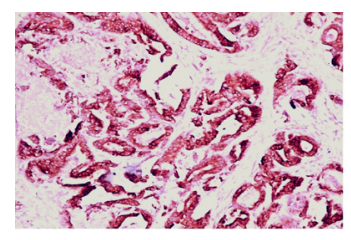

Figure 3. Grade I Colorectal Adenocarcinoma. Note diffuse brown cytoplasmic staining denoting Cox-2 positivity (Immunoperoxidase, DABx40)

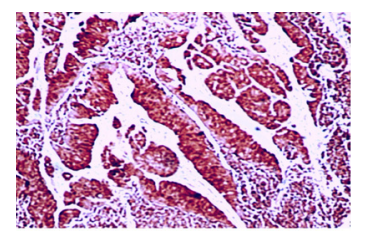

Figure 4. Colorectal Adenocarcinoma with Mucoid Activity. Note brown cytoplasmic staining of Cox-2; (immunoperoxidase, DAB x200) 
Table 1. Correlation of COX-2 Immunoreactivity to the Site of the Tumor in the Large Intestine

\begin{tabular}{lccr}
\hline Site & COX2 ve+ & COX2 ve- & Total \\
\hline Right side & $7(63.6 \%)$ & $4(36.4 \%)$ & 11 \\
Transvrse clolon & $7(77.7)$ & $2(22.3 \%)$ & 9 \\
Left side \& rectum & $13(86.7 \%)$ & $2(13.3 \%)$ & 15 \\
Total & $27(77 \%)$ & $8(23 \%)$ & 35 \\
\hline
\end{tabular}

Chi square 1.912, D.F. 2, p= 0.3845, not significant

Table 2. Correlation of COX-2 Immunoreactivity to the Gross Appearance of the Studied Cases

\begin{tabular}{lrrr}
\hline Gross & COX2 ve+ & COX2 ve- & Total \\
\hline Fungating & $17(81 \%)$ & $4(19 \%)$ & 21 \\
Ulcerating & $8(73 \%)$ & $3(27 \%)$ & 11 \\
Annular & $2(67 \%)$ & $1(33 \%)$ & 3 \\
Total & $27(77 \%)$ & $8(23 \%)$ & 35 \\
\hline
\end{tabular}

Table 3. Correlation of COX-2 Immunoreactivity to the Size of the Studied Case

\begin{tabular}{lclr}
\hline Size in maximum diameter $(\mathrm{cm})$ & COX2 ve+ & COX2 ve- & Total \\
Up to 5 & $15(71.4 \%)$ & $6(28.6 \%)$ & 21 \\
\hline More than 5-10 & $9(82 \%)$ & $2(18 \%)$ & 11 \\
More than 10 & $2(66.7 \%)$ & $1(33.3 \%)$ & 3 \\
Total & $27(77 \%)$ & $8(23 \%)$ & 35 \\
\hline
\end{tabular}

Table 4. Correlation of COX-2 Immunoreactivity to the Histological Grade of the Studied Cases

\begin{tabular}{lccc}
\hline Grade & COX2 ve+ & COX2 ve- & Total \\
\hline I & $5(71 \%)$ & $2(29 \%)$ & 7 \\
II & $12(67 \%)$ & $6(33 \%)$ & 18 \\
III & $10(100 \%)$ & 0 & 10 \\
Total & $27(77 \%)$ & $8(23 \%)$ & 35 \\
\hline
\end{tabular}

Chi square 1.912, D.F. $2, \mathrm{p}=0.3845$, not significant

Table 5. Correlation of COX-2 Immunoreactivity to The Lymph Nodes Involvement In The Studied Cases

\begin{tabular}{lccc}
\hline LNS & COX2 ve+ & COX2 ve- & Total \\
\hline +ve & $15(79 \%)$ & $4(21 \%)$ & 19 \\
-ve & $12(75 \%)$ & $4(25 \%)$ & 16 \\
Total & $27(77 \%)$ & $8(23 \%)$ & 35 \\
\hline
\end{tabular}

Fisher exact test, $\mathrm{p}=0.5475$, not significant

Table 6. Correlation of Cox-2 Immunoreactivity to the Duke's Stage of The Studied Cases

\begin{tabular}{lccr}
\hline Stage & COX2 ve+ & COX2 ve- & Total \\
\hline A & 0 & 0 & 0 \\
B & $12(80 \%)$ & $3(20 \%)$ & 15 \\
C & $15(79 \%)$ & $4(21 \%)$ & 19 \\
D & 0 & $1(100 \%)$ & 1 \\
Total & $27(77 \%)$ & $8(23 \%)$ & 35 \\
\hline Chi square 3.48, & &
\end{tabular}

Table 7. Correlation of COX-2 Immunoreactivity to Vascular Invasion in the Studied Cases

\begin{tabular}{lccr}
\hline Vascular invasion & COX2 ve+ & COX2 ve- & Total \\
\hline Positive & $3(75 \%)$ & $1(25 \%)$ & 4 \\
Negative & $24(77.4 \%)$ & $7(22.6 \%)$ & 31 \\
Total & $27(77 \%)$ & $8(23 \%)$ & 35 \\
\hline
\end{tabular}

Fisher exact test $\mathrm{p}=0.6648$, not significant
Table 8. Correlation of Cox-2 Immunoreactivity to the Duke's Stage of The Studied Cases

\begin{tabular}{llcc}
\hline Perineural invasion & COX2 ve+ & COX2 ve- & Total \\
\hline Positive & $2(100 \%)$ & 0 & 2 \\
Negative & $25(76 \%)$ & $8(24 \%)$ & 33 \\
Total & $27(77 \%)$ & $8(23 \%)$ & 35 \\
\hline
\end{tabular}

Fisher exact test $\mathrm{p}=0.5899$, not significant

staging, vascular invasion and perineural invasion are consolidated in Tables 1 to 8 respectively.

\section{Discussion}

Positive immunoreactivity to COX-2 is detected by brown cytoplasmic staining in tumor cells of positive cases, we have also detected COX-2 immunoreactivity in stromal cells such as mononuclear cells, fibroblasts, endothelial cells, and smooth muscle cells. There is insignificant relationship between COX-2 immunostaining and site, size and gross appearance of the tumor (where most of cases in all sites are positive for COX-2). Similar results were reported by (Tomozawa et al., 2000), after working on 63 patients with advanced colorectal cancer; in which COX-2 positivity appear in all cases examined; found that there was no significant correlation between COX-2 expression and tumor location, age, sex, tumor size, histological type, depth of invasion, lymphatic or venous invasion, lymph-nodemetastasis. According to (Soumaoro et al., 2004) $51 \%$ of histological grading belongs to Grade II in the colorectal adenocarcinoma cases this result is similar to our work. The relation between COX-2 positivity and histological grade is statistically insignificant, many studies agreed with this. According to the study (Fux et al., 2005) the immunohistochemical assessment, COX-2 expression in tumor epithelial cells was not related to grade, stage of tumor, node metastasis or recurrence. Similar to these results were (Kim et al., 2004). There was no significant statistical correlation, relating COX-2 to Dukes' staging.

The correlation between COX-2 immunoreactivity and lymph nodes involvement is statistically insignificant, as most of positive cases for lymph nodes involvement ( $79 \%$ of them), and negative cases ( $75 \%$ of them) were positive for COX-2 immunostaining. In agreement with (Joo et al., 2007) as COX-2 protein was detected in $70 \%$ (42/60 of cases) of colorectal carcinoma tissues. However, No significant correlation was found between COX-2 expression and various clinicopathological parameters including lymph node metastasis, histological grade, tumor size, depth of invasion, distant metastasis, or stage of tumor and this agreed also with (Kim et al., 2004). COX-2 positivity was not significantly related to presence of vascular invasion or Perineural invasion. Also (Al-Maghrabi J et al., 2012) revealed that there was no significant correlation between COX-2 expression and sex, age, grade or tumor location. However they found significant correlation with tumor stage and distant metastasis. (Elzagheid et al., 2013) found that there was no significant correlation with age, gender, tumor grade or lymph node status. However, univariate survival analysis of metastases showed borderline association with COX2 
expression in that patients with metastases with $\mathrm{COX} 2$ positive tumors were alive for shorter periods of time compared with patients whose tumors had no COX2 expression but they concluded that $\mathrm{COX}-2$ expression has shown a significant correlation with tumor stage.

(Zhang $\mathrm{H}$ and Sun XF, 2002) were unable to find any relationship of COX-2 with patient age, sex, tumor growth pattern, apoptosis, and patient survival but COX-2 was related to proliferative activity, tumor location, Dukes' stage, and differentiation. These results further support the evidence that COX-2 may be involved in tumorigenesis and development of colorectal cancer.

Latest study conducted by (Xu YS et al., 2014) supports that cyclooxygenase- 2 promoter $765 \mathrm{G} / \mathrm{C}$ polymorphism plays no significant role in developing colorectal cancer.

Since the last decade several studies have been done to prevent and treat the colorectal cancer. The study done by (Harris RE, 2007) confirmed that COX-2 blockade is effective for both cancer prevention and therapy. It has been reported MMPs are linked to COX-2-mediated carcinogenesis (Manal Ali Shalaby et al., 2014) therefore MMP2 regulatory polymorphisms could be considered as protective mechanism. According to (Christudoss $\mathrm{P}$ et al., 2013) the use of aspirin, vitamin $C$ and zinc have chemoprotective role against progression of colonic carcinoma. It is suggested by (Fatemi SR et al., 2010) that there is an increased risk of developing colorectal cancer among first-degree relatives of patients with colorectal cancer. The use of NSAID regulate gene expression Of COX -1 and COX-2, hence it has a chemo preventive activity (Bottone FG Jr et al., 2004).

In conclusion, the presences of COX-2 protein over expression in colorectal carcinoma in contrast with normal mucosa suggest that COX-2 may play a role in cell proliferation in carcinogenesis.

There was no association between COX-2 expression and the clinicopathological features shown, as there was no significant correlation between COX-2 expression and tumor size, tumor location, gross picture, histological type, venous or Perineural invasion, lymph node metastasis and Dukes' classification.

\section{References}

Al-Maghrabi J, Buhmeida A, Emam E, et al (2012). Cyclooxygenase- 2 expression as a predictor of outcome in colorectal carcinoma. World J Gastroenterol, 18, 1793-9.

Bottone FG, Martinez, JM, Alston-Mills B, Eling TE (2004). Gene modulation by Cox-1 and Cox- 2 specific inhibitors in human colorectal carcinoma cancer cells. Carcinogenesis, 25, 349-57.

Christudoss P, Selvakumar R, Pulimood AB, et al (2013). Protective role of aspirin, vitamin $\mathrm{C}$, and zinc and their effects on zinc status in the DMH-induced colon carcinoma model. Asian Pac J Cancer Prev, 8, 4627-34.

Dempke W, Rie C, Grothey A (2001). Cyclooxygenase-2: A novel target for cancer chemotherapy. J Cancer Res Clin Oncol, 127, 411-7.

Elzagheid A, Emaetig F, Alkikhia L, et al (2013). High cyclooxygenase- 2 expression is associated with advanced stages in colorectal cancer. Anticancer Res, 33, 3137-43.
Fatemi SR, Malek FN, Shivarani S, et al (2010). Prevalence of colorectal cancer in relatives of Iranian patients diagnosed with colorectal cancer. Asian Pac J Cancer Prev, 1, 91-3.

Fux R, Schwab M, Thon KP, Gleiter CH, Fritz P (2005). Cyclooxygenase-2 expression in human colorectal cancer is unrelated to overall patient survival. Clin Cancer Res, 11, 4754-60.

Harris RE (2007): Cyclooxygenase-2 (COX-2) and the inflammogenesis of cancer. Subcell Biochem, 42, 93-126.

Jemal A, Bray F, Center MM, et al (2011). Global cancer statistics. CA Cancer J Clin, 61, 69-90.

Kim JY,Lim SJ, Park K (2004). Cyclooxygenase-2 and c-erbB-2 expression in colorectal carcinoma assessed using tissue microarrays. Appl Immunohistochem Mol Morphol, 1, 67-70.

Karahan N, Güney M, Baspinar S, et al (2007). Expression of gelatinase (MMP-2 and MMP-9) and cyclooxygenase-2 (COX-2) in endometrial carcinoma. Eur J Gynaeol Oncol, 28, 184-8.

Kawamori T, Uchiya N, Sugimura (2003). Enhancement of colon carcinogenesis by prostaglandin E2 administration. Carcinogenesis, 24, 985-90.

Sameer AS, Shah ZA, Syeed N, et al (2010). NAD(P) $\mathrm{H}$ :quinoneoxidoreductase 1 (NQO1) Pro187Ser polymorphism and colorectal cancer predisposition in the ethnic Kashmiri population. Asian Pac J Cancer Prev, 11, 209-13.

Shalaby MA, Nounou HA, Ms A, et al (2014). Associations between single nucleotide polymorphisms of COX-2 and MMP-2 genes and colorectal cancer susceptibility in the Saudi population. Asian Pac J Cancer Prev, 12, 4989-94

Sonoshita M, Takaku K, Oshima M (2002). Cyclooxygenase-2 expression in fibroblasts and endothelial cells of intestinal polyps. Cancer Res, 62, 6846-9.

Soumaoro LT, Uetake H, Higuchi T (2004).Cyclooxygenase-2 expression, Asignificant prognostic indicator for patients with colorectal cancer. Clin Cancer Res, 10, 8465-71.

Smyrk TC (2002). Colorectal cancer pathology. In Gastrointestinal oncology principles and practice. Lippincott Williams and Wilkins, Philadelphia, 717-30.

Tsujii M, Kawano S, Tsuji S, et al (1998). Cyclooxygenase regulates angiogenesis induced by colon cancer cells. Cell, 93, 705-16.

Tomozawa S, Tsuno NH, Sunami E (2000). Cyclooxygenase -2 overexpression correlates with tumour recurrence, especially haematogenous metastasis of colorectal cancer. Br J Cancer, 83, 324-8.

Tuynman JB, Buskens, Kemper K(2005). Neo-adjuvant selective cox-2 inhibition down-regulates important oncogenic pathway with esophageal adenocarcinoma. Ann Sur, 242, 840-9.

Wu AW, Gu J, Ji JF, Li ZF, Xu GW (2003). Role of COX-2 in carcinogenesis of colorectal cancer and its relationship with tumor biological characteristics and patients' prognosis. World J Gastroenterol, 9, 1990-4.

Xu YS, Zhao B, Long CY, et al (2014).Cyclooxygenase-2 promoter $765 \mathrm{C}$ increase of digestive tract cancer risk in the Chinese population: a meta-analysis. Asian Pac J Cancer Prev, 11, 4563-6.

Zhou LH, Hu Q, Sui H, et al (2012). Tanshinone II--a inhibits angiogenesis through down regulation of COX-2 in human colorectal cancer. Asian Pac J Cancer Prev, 13, 4453-8.

Zhang H, Sun XF (2002). Overexpression of cyclooxygenase-2 correlates with advanced stages of colorectal cancer. Am J Gastroenterol, 97, 1037-41. 